\title{
НАУЧНЫЕ ПУБЛИКАЦИИ
}
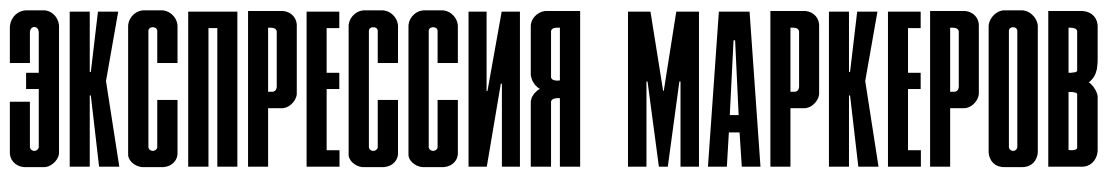

УДК 616-006.66+616.34-006.6

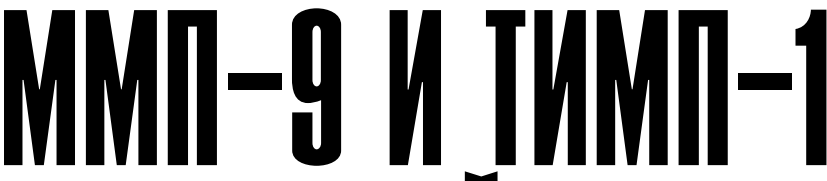

В РАКОВОЙ

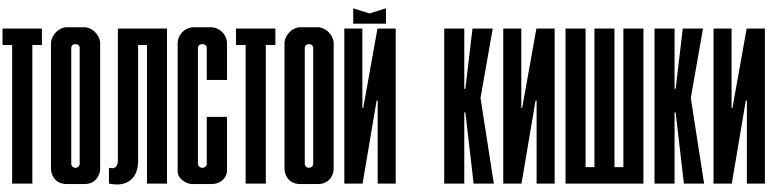

Марина Деревянко, научный сотрудник лаборатории

«Центр электронной и световой микроскопии» Института физиологии НАН Беларуси;

mari. derewianko@mail.ru

Светлана Рябцева,
заведующий
лабораторией
«Центр электронной
и световой микроскопии»
Института физиологии
НАН Беларуси,
кандидат
медицинских наук;
sveta. rjabceva@tut. by

Михаил Фридман,

заведующий

патологоанатомической

лабораторией

Минского городского

клинического

онкологического

диспансера,

доктор медицинских наук;

mfridman@tyt.by

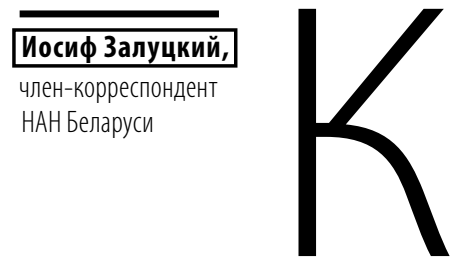

олоректальный рак (КРP) - злокачественное эпителиальное новообразование толстой кишки, занимающее третье место в мире по частоте среди всех злокачественных новообразований и четвертое - среди причин онкологической летальности [1]. Ежегодно регистрируют более миллиона пациентов с КРР и около 700 тыс. летальных исходов. Развитие отдаленных метастазов является основной причиной смертности и выявляется у 25\% пациентов при первичном обращении $[1,2]$. По данным Белорусского канцер-регистра, в течение последних десятилетий отмечается стойкий рост заболеваемости раком данной локализации. И если количество умерших от рака легких, молочной железы и желудка снижается, то от КРР растет [3]. Поэтому актуальны исследования механизмов 
метастазирования аденокарциномы толстой кишки и поиск маркеров для ранней диагностики/ прогноза этого процесса.

В основе образования вторичных очагов злокачественных новообразований лежит совокупность многих обстоятельств, в частности важно взаимодействие опухолевых клеток с микроокружением, в результате которого происходит ремоделирование тканей с разрушением внеклеточного матрикса $[4,5]$. Ведущая роль в деградации структурных белков соединительной ткани, таких как коллагены, эластин, протеогликаны, гликопротеины, молекулы межклеточных и белково-клеточных контактов, принадлежит матриксным металлопротеиназам (ММП) [6]. Кроме того, они регулируют функции биологически активных молекул, включая факторы роста, молекулы адгезии и др. [6, 7]. Установлено, что ММП принимают участие в неоангиогенезе и отборе резистентных к апоптозу опухолевых клеток, а в ряде злокачественных опухолей индуцируют эпителиально-мезенхимальный переход, в результате которого раковые клетки приобретают способность к миграции [7]. Описано более 20 ферментов семейства ММП: коллагеназы (ММП-1, ММП-8 и ММП-13), желатиназы (ММП-2 и ММП-9), стромелизины (ММП-3 и ММП-10), матрилизины (ММП-7), мембраносвязанные ММП и др. [4]. ММП-2 и ММП-9 гидролизуют основной структурный белок базальной мембраны коллаген IV типа, поэтому претендуют на роль факторов прогноза метастазирования [6-8].

Каталитическая активность ММП корригируется тканевыми ингибиторами металлопротеиназ
(ТИМП), наиболее изучены ТИМП-1 и ТИМП-2. Нарушение баланса уровня протеаз и их ингибиторов, как полагают, играет решающу роль в ремоделировании внеклеточного матрикса и поддержании его гомеостаза [9-11]. Показано, что в тканях ряда злокачественных опухолей наблюдается гиперэкспрессия ММП-9, ММП-2 и снижение уровня ТИМП-1 и ТИМП-2, что связано с образованием метастазов и плохим прогнозом течения заболевания $[12,13]$. Эта тема заслуживает внимания и потому, что данные о роли матриксных металлопротеиназ и их ингибиторов в распространении КРР неоднозначны [14-19].

Настоящая работа посвящена изучению характера экспрессии маркеров ММП-9 и ТИМП-1 в структурных компонентах рака толстой кишки в зависимости от характера метастазирования опухоли.

Материалом для исследования послужили фрагменты стенки толстой кишки с опухолью пациентов, прооперированных по поводу аденокарциномы данной локализации в Минском городском клиническом онкологическом диспансере в 2014 и 2015 гг. Иммуногистохимический анализ экспрессии маркеров ММП-9 и ТИМП-1 проводили на парафиновых срезах толщиной 5 мкм. Использовали моноклональные антитела ММП-9 (Dako) в рабочем разведении 1:100 (демаскировка антигена в буфере рН 9,0 на водяной бане, инкубация с первичными антителами 60 минут при температуре $\left.23{ }^{\circ} \mathrm{C}\right)$; ТИМП-1 (Abcam) - 1:5000 (демаскировка антигена в буфеpe $\mathrm{pH}$ 9,0 в микроволновом режиме при мощности 700W, инкубация с первичными антителами на протяжении 18 ч при температуре $4{ }^{\circ} \mathrm{C}$ ).

Рассматривали микропрепараты и изготавливали микрофотографии с помощью светового микроскопа OptecBK 5000 с цифровой камерой, ув. $\times 200$ и $\times 400$. Иммуногистохимическую реакцию к ММП-9 оценивали по наличию окрашивания в структурных компонентах опухоли без акцента на интенсивность, экспрессию ТИМП-1 - по положительной реакции в компонентах аденокарциномы и полуколичественным методом с учетом яркости окрашивания клеток в эпителиальном и стромальном компонентах опухоли; представляли в баллах: отрицательная - 0, слабо положительная - 1, умеренная - 2, высоко выраженная - 3 балла.

Статистический анализ проводился в программе Statistica 6.1. Нулевая гипотеза об однородности групп проверялась непараметрическими методами: при сравнении двух групп использовали U-критерий Манна - Уитни, более двух групп - Н-критерий Краскала - Уоллиса $(\mathrm{p}<0,05)$. Для оценки связи между изучаемыми признаками рассчитывали коэффициент корреляции Спирмена (rs).

В исследование были включены 69 пациентов, которые были разделены на три группы согласно TNM-классификации.

Первую группу составили 19 пациентов (11 (57,9\%) мужчин, 8 $(42,1 \%)$ женщин, средний возраст $63,52 \pm 2,81$ года) с местным распространением КРP (pT1-4N0M0). Положительная иммуногистохимическая реакция к маркеру ММП-9 определялась в опухолевых клетках (4/21\%) и в отдельных, разрозненно лежащих крупных эпителиоидно-подобных клетках (5/26,3\%) (рисунок). Последние 
имели овальную или веретеновидную форму со светлым округлым ядром, обладали признаками эпителиальной и мезенхимальной клетки и встречались как в зоне глубокой инвазии опухоли, так и в ее толще. При этом у 3 (15,8\%) пациентов отмечалась сочетанная экспрессия ММР-9 в эпителиальных комплексах и отдельных эпителиоидно-подобных клетках опухоли. Положительная экспрессия маркера ММП-9 также выявлена в фибробластах (у 7 чел., 36,8\%) и воспалительном инфильтрате $(12 / 63,1 \%)$. Сочетанная экспрессия фибробластами и клетками воспаления выявлена в $3(15,8 \%)$ случаях (таблица). Положительная реакция к маркеру ТИМП-1 обнаружена в эпителии (17/89,5\%) и строме $(15 / 78,9 \%)$ опухоли разной выраженности. Интенсивность реакции к маркеру ТИМП-1 в опухолевых клетках варьировала от слабой $(4 / 23,5 \%)$ и умеренной $(3 / 17,6 \%)$ до выраженной (10/58,8\%). В строме (без разделения на фибробласты и воспалительную инфильтрацию) преобладала умеренная активность ТИМП-1 (9/60\%), слабая и выраженная встречались реже- $4 / 26,7 \%$ и $2 / 13,3 \%$ соответственно.

Во вторую группу исследования были включены 25 пациентов (13 (52\%) мужчин, 12 (48\%) женщин, средний возраст $67,56 \pm 1,61$ года) с локально-регионарным распространением рака толстой кишки (pT1-4N1-2M0). Экспрессия маркера ММП-9 также выявлена в эпителии опухоли (7/28\%) и в эпителиоидно-подобных клетках (12/48\%). При этом у 5 (20\%) чел. отмечалась сочетанная экспрессия ММР-9 в эпителиальных комплексах и эпителиоидно-подобных клетках опухоли. Положительная реакция
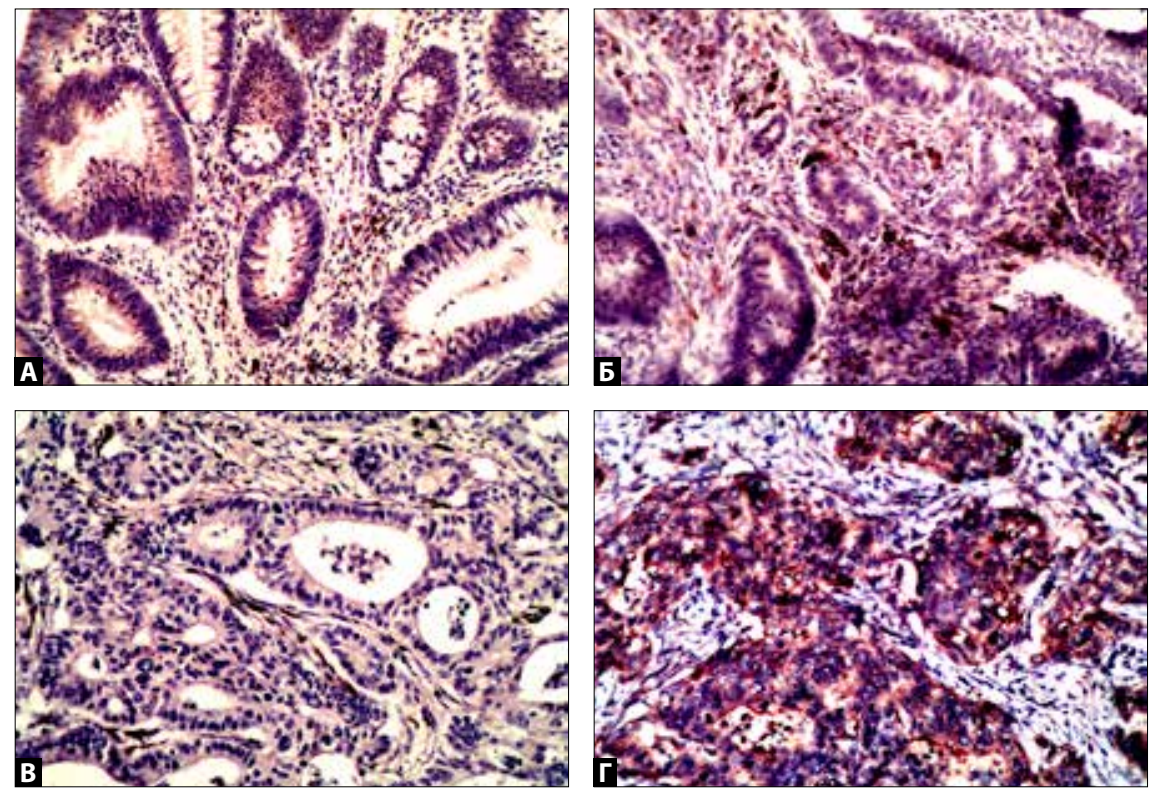

Рисунок. Характер экспрессии маркеров ММП-9 и ТИМП-1 в структурах рака толстой кишки (ув. 200): А - экспрессия ММП-9 в эпителии и клетках воспаления (указано стрелкой); 5 - экспрессия ММП-9 крупными эпителиоидно-подобными клетками; В - экспрессия ММП-9 фибробластами; Г - экспрессия ТИМП-1 опухолевыми клетками

\begin{tabular}{lcc|cc}
\hline \multirow{2}{*}{ Группа } & \multicolumn{2}{c|}{ ММП-9 } & \multicolumn{2}{c}{ тИМП-1 } \\
\hline Первая & $7 / 47,3 \%$ & $16 / 84,2 \%$ & $17 / 89,5 \%$ & $15 / 78,9 \%$ \\
Вторая & $14 / 56 \%$ & $18 / 81,8 \%$ & $22 / 88 \%$ & $18 / 81,8 \%$ \\
Третья & $17 / 68 \%$ & $22 / 88 \%$ & $22 / 88 \%$ & $18 / 81,8 \%$ \\
\hline
\end{tabular}

Таблица. Локализация экспрессии ММП-9 и ТИМП-1 в опухолевой ткани пациентов групп исследования, абс./\%

к маркеру ММП-9 также определялась в фибробластах (12/48\%) и клетках воспалительного инфильтрата (16/60\%) стромы, их сочетание отмечалось в 9 (36\%) случаях (см. таблицу). Экспрессия маркера ТИМП-1 разной степени обнаружена в эпителии (22/88\%) и строме $(18 / 81,8 \%)$. В эпителиальном компоненте практически поровну констатировалась слабая $(8 / 36,4 \%)$, умеренная $(7 / 31,8 \%)$ и выраженная $(7 / 31,8 \%)$ реакция; в строме преобладала выраженная $(8 / 44,4 \%)$, слабая и умеренная - по 5 чел. (по 27,8\%).

Третья группа - 25 пациентов (13 (52\%) женщин, 12 (48\%) мужчин, средний возраст $63,72 \pm 1,81$ года) с диссеминированным раком толстой кишки (pT1-4N1-2M1). Экспрессия маркера ММП-9 наблюдалась в эпителии опухоли $(8 / 32 \%)$ и в эпителиоидно-подобных клетках (14/56\%), у $5(20 \%)$ чел. она была сочетанная; положительная реакция также определялась в фибробластах (12/48\%) и клетках воспалительного инфильтрата (15/60\%) стромы, сочетанная - у 5 (20\%) пациентов. Повышение уровня ТИМП-1 выявлено в эпителии $(22 / 88 \%)$ и строме $(18 / 81,8 \%)$ опухоли (см. таблицу). В эпителиальном компоненте преобладала выраженная (9/40\%) 
и слабая $(8 / 36,4 \%)$ интенсивность окрашивания, умеренная наблюдалась в $5(22,7 \%)$ случаях. В стромальном компоненте КРР преобладала слабая реакция $(7 / 38,9 \%)$, умеренная и выраженная зарегистрированы у $5(27,8 \%)$ и $6(33,3 \%)$ пациентов соответственно.

По анализируемым показателям статистически достоверных отличий в группах исследования не выявлено, что свидетельствует об изменениях активности матриксной металлопротеиназы и ТИМП-1 вне зависимости от метастатического потенциала рака. Однако установлена взаимосвязь между повышением уровня маркеров в структурных компонентах КРР. Характер экспрессии ТИМП-1 в строме находился в прямой корреляционной взаимосвязи с интенсивностью положительной реакции данного маркера в опухолевых клетках $\left(r_{s}=0,32\right)$. Следовательно, для рака толстой кишки нарастание активности ТИМП-1 в эпителии опухоли сопровождается увеличением интенсивности положительной реакции к данному маркеру и в строме. Между выраженностью экспрессии маркеров ТИМП-1 и ММП-9 в строме опухоли выявлена прямая корреляционная взаимосвязь $\left(\mathrm{r}_{\mathrm{s}}=0,30\right)$, в большей степени - с активацией ММП-9 в клетках воспаления $\left(\mathrm{r}_{\mathrm{s}}=0,47\right)$. Интенсивность положительной реакции ММП-9 в стромальном компоненте КРР (фибробласты и клетки воспаления) обратно пропорциональна экспрессии данного маркера в эпителиальных комплексах $\left(\mathrm{r}_{\mathrm{s}}=-0,36\right)$. Нарастание интенсивности иммуногистохимической реакции к ММП-9 в эпителиоидно-подобных клетках рака сопровождалось пропорциональным нарастанием выраженности экспрессии данного маркера в фибробластах $\left(\mathrm{r}_{\mathrm{s}}=0,41\right)$ и обратным в воспалительном инфильтрате $\left(\mathrm{r}_{\mathrm{s}}=-0,35\right)$.

Таким образом, полученные данные свидетельствуют о неравномерном распределении ММП-9 и тканевого ингибитора между опухолевыми и стромальными клетками рака толстой кишки с преобладанием экспрессии матриксной металлопротеиназы в клетках стромы, а ингибитора - в клетках опухоли, что подтверждает участие стромального микроокружения в опухолевом процессе. Взаимосвязи уровня и наличия экспрессии ММП-9 и ТИМП-1 эпителиальными и стромальными клетками с риском развития метастазов не выявлено. Однако следует отметить некоторое нарастание активности обоих маркеров во всех компонентах опухоли с развитием регионарного и отдаленного метастазирования. Также установлены прямая корреляционная взаимосвязь активации исследуемых маркеров в стромальном компоненте опухоли и отсутствие такой зависимости - в эпителиальном.

- Summary. The article presents the results of an immunohistochemical study of the expression of the markers matrix metalloproteinase- 9 and tissue inhibitor of matrix metalloproteinases-1 in patients with colon adenocarcinoma. The structural components in which expression of MMP-9 is possible are revealed: tumor cells, large epithelioid-like cells, inflammatory cells, fibroblasts. The findings suggest that the protease and its tissue inhibitor are unevenly distributed between tumor and stromal colon cancer cells. There is an increase in the frequency of a positive reaction in the epithelial cells of the tumor in a state of epithelial-mesenchymal transition in patients with metastases.

- Keywords: colon cancer, matrix metalloproteinase-9, tissue inhibitor of matrix metalloproteinases-1, stromal microenvironment.

https://doi.org/10.29235/1818-9857-2019-1-77-80

\section{СПИСОК ИСПОЛЬЗОВАННЫХ ИСТОЧНИКОВ}

1. Early colon cancer: ESMO Clinical Practice Guidelines for diagnosis, treatment and follow-up / R. Labianca [et al.] // Annals of Oncol. 2013. Vol. 24. P. 64-72.

2. Cancer incidence and mortality patterns in Europe: Estimates for 40 countries in 2012 / J. Ferlay [et al.] // Europ. J. of Cancer. 2013. Vol. 49. P. 1374-1403.

3. Суконко 0.Г. Статистика онкологических заболеваний в Республике Беларусь / 0.Г. Суконко.- Минск, 2012.

4. Adjei I.M. Modulation of the tumor microenvironment for cancer treatment: a biomaterials approach / I. M. Adjei, S. Blanka // J. of Functional Biomaterials. 2015. Vol. 6. P. 81-103.

5. Dudas J. Supportive and rejective functions of tumor stroma on tumor cell growth, survival, and invasivity: the cancer evolution / J. Dudas // Mol. and Cell. Oncol. 2015. Vol. 5, N44. P. 1-2.

6. Malemud C. Matrixmetalloproteinases (MMPs) in health and disease: an overview / C. Malemud // Front Biosci. 2006. Vol. 11. P. 1696-1701.

7. Матриксные металлопротеиназы, их роль в физиологических и патологических процессах / Л.Н. Рогова [и др.] // Вестник новых медицинских технологий. 2011. Т. 181, №2. С. 86-89.

8. Ганусевич И.И. Роль матриксных металлопротеиназ (ММП) при злокачественных новообразованиях / И.И. Ганусевич // Онкология. 2010 №2. C. 108-117.

9. Matrix metalloproteinases: regulators of the tumor microenvironment / K. Kessenbrock [et al.] // Cell. 2010. Vol. 141, N1.P. 52-67.

10. Regulation of matrix metalloproteinase activity in health and disease / E. Hadler-Olsen [et al.] // FEBS J. 2011. Vol. 278, N1. P. $28-45$.

11. Visse R. Matrix metalloproteinases and tissue inhibitors of metalloproteinases: structure, function, and biochemistry / R. Visse, H. Nagase // Circ Res. 2003. Vol. 92, N8. P. 827-839.

12. Increased expression of matrix metallopro-teinase-2 (MMP-2) predicts tumour recurrence and unfavourable outcome in non-small cell lung cancer / T. Leinonen [et al.] // Histol. Histopathol. 2008. Vol. 23, N6. P. 693-700.

13. Prognostic significance of MMP-9 and TIMP-1 serum and tissue expression in breast cancer / Z. Wu [et al.] // Int. J. Cancer. 2008. Vol. 122, N9 P. 2050-2056.

Статья поступила в редакцию 20.08.2018 г. 